\title{
CONCEPÇÕES DE TECNOLOGIA DE GRADUANDOS DO ESTADO DE SÃO PAULO E SUAS IMPLICAÇÕES EDUCACIONAIS: BREVE ANÁLISE A PARTIR DE MODELAGEM DE EQUAÇÕES ESTRUTURAIS*
}

\section{Conceptions of technology of graduates of the State of Sao Paulo and its implications for education: brief analysis based on structural equation modeling}

\author{
Estéfano Vizconde Veraszto ${ }^{1}$. Dirceu da Silva ${ }^{2}$. \\ Eder Pires de Camargo ${ }^{3}$ • Jomar Barros Filho ${ }^{4}$
}

\begin{abstract}
Resumo: Este trabalho apresenta parte dos resultados de uma pesquisa desenvolvida com alunos de graduação de diferentes regiões do Estado de São Paulo, que buscou entender melhor as relações entre a sociedade e as concepções e atitudes frente ao desenvolvimento tecnológico. Constatando que mídia, academia e documentos oficiais que regulamentam a educação entendem e apresentam a tecnologia de forma distinta e, muitas vezes, contraditórias, este trabalho busca fazer uma revisão bibliográfica sobre as diferentes formas de conceituar este termo, para, a partir de então, desenvolver uma escala de Likert para o mapeamento das concepções de estudantes. Utilizando a análise confirmatória da Modelagem de Equações Estruturais, este trabalho conclui que a amostra pesquisada apresenta uma visão clássica, mas ultrapassada, do que venha a ser a tecnologia, associando ciência e técnica sem distinções ou pontos de vistas críticos.
\end{abstract}

Palavras-chave: Tecnologia. Modelagem de equações estruturais. Estudos CTS.

\begin{abstract}
This paper presents some results from a study of undergraduate students from different regions of the State of São Paulo that sought to better understand the relationships between society and perceptions and attitudes towards technological development. Noting that the media, academia and official documents regulating education understand and present the technology in a distinct and often contradictory ways, this paper seeks to review existing literature on the different ways to conceptualize this term, and thereafter, to develop a Likert' scale for mapping the concepts of students. Using the confirmatory analysis of structural equation modeling, this research concludes that the sample studied shows a classical view, but outdated, what means technology, by linking it to science and technology without distinction or critical viewpoints.
\end{abstract}

Keywords: Technology. Structural equation modeling. STS studies.

\footnotetext{
* Pesquisa parcialmente financiada pela Coordenação de Aperfeiçoamento de Pessoal de Nível Superior (CAPES). ${ }^{1}$ Universidade Federal de São Carlos (UFSCar), Departamento de Ciências da Natureza, Matemática e Educação, Rodovia Anhanguera, Km 174, CEP 13604-900, Araras, SP, Brasil. E-mail: estefanovv@cca.ufscar.br

${ }^{2}$ Universidade Estadual de Campinas, Faculdade de Educação, Campinas, SP, Brasil.

${ }^{3}$ UNESP - Univ Estadual Paulista, Faculdade de Engenharia, campus de Ilha Solteira, Departamento de Física e Química, Ilha Solteira, SP, Brasil.

${ }^{4}$ Faculdade Municipal prof. Franco Montoro, Mogi Guaçu, SP, Brasil. In memoriam.
} 
Veraszto, E. V. et al.

\section{Introdução}

O nosso dia a dia presencia uma quantidade enorme de informações veiculadas pela internet e pela mídia televisiva e impressa. Em muitos discursos, é possível perceber que a palavra tecnologia se faz presente. Noticiários de diversas naturezas empregam o termo, muitas vezes, como um complemento para alguma informação que diz respeito ao exercício do poder ou ao status quo social. A partir de uma leitura mais atenta de jornais e revistas ou de um olhar mais crítico a programas televisivos, não fica difícil constatar que, junto com o emaranhado de opiniões e informações, pontos de vista desencontrados a respeito da tecnologia são emitidos constantemente (BARROS FILHO et al., 2009, 2010; SILVA; BARROS FILHO, 2001).

Contudo, essa confusão não se limita ao senso comum ou a programações populares de televisão. Seja em artigos de divulgação científica (ABREU, 2008; ADRIÃO, 2008; AULER; DELIZOICOV, 2006; BARROS FILHO et al., 2009, 2010; FIRME; AMARAL, 2008; JACINSKI; SUSIN; BAZZO, 2008; PINHEIRO; SILVEIRA; BAZZO, 2007; REIS, 2009; RICARDO; CUSTÓDIO; RESENDE JUNIOR, 2007; VERASZTO, 2004, 2009; VIEIRA; MARTINS, 2005) ou em documentos oficiais, como: a Lei de Diretrizes e Bases (BRASIL, 1996), os Parâmetros Curriculares Nacionais (BRASIL, 1997), o Plano Nacional de Educação (BRASIL, 2001), e documentos do Fórum de Pró-Reitores de Graduação das Universidades Brasileiras $(2000,2001)$, o termo tecnologia é utilizado sem um consenso.

A divergência de opiniões e a pluralidade de interpretações podem derivar do fato de que o processo de desenvolvimento tecnológico englobe os mais distintos setores e interesses sociais. Assim, essa complexidade se faz ecoar de forma restrita e limitada na mídia, na produção acadêmica e na elaboração de currículos e programas escolares. Contudo, quando um norte não é apontado, propostas educacionais bem-intencionadas podem não sair do papel pelo simples fato de não considerarem o que os indivíduos sabem ou aquilo que a sociedade demanda (VERASZTO, 2009).

Este fato não é atual e, também, não mudou com o passar das últimas décadas. Silva e Barros Filho (2001) já constataram que o documento responsável por basilar os cursos de graduação no território nacional (BRASIL, 2001), em doze páginas, utilizou dezessete vezes o termo tecnologia, com conotações, muitas vezes, conflitantes ou equivocadas, como quando atribui à palavra o falso sentido de que tecnologia é sinônimo de artefato tecnológico. Também foram encontrados termos que apontam a tecnologia sendo descrita como sinônimo de ciência ou de técnica, ou, ainda, como sendo uma atividade neutra e universal.

Discussões variadas que, mesmo oriundas de intenções positivas, muitas vezes, distanciam as pessoas de um posicionamento mais crítico. Mesmo assim, este artigo não tem a intenção de criticar tudo o que se fala ou se escreve sobre tecnologia, mas, sim, mostrar que a dificuldade que existe em definir esse termo reflete toda uma história de estudos ambíguos e diversificados dos desenvolvedores e consumidores de tecnologias e artefatos tecnológicos. Divergências essas que ocasionam um impacto significativo no âmbito educacional, tendo em vista que a sociedade passa, constantemente, por transformações provindas do desenvolvimento tecnológico, e, nos dias atuais, sente, cada vez mais, a necessidade de que as novas escolhas tecnológicas sejam frutos de relações democráticas conscientes, e não detentoras de manutenções hegemônicas de poder. 
Concepções de tecnologia de graduandos ...

Se a intenção é promover uma educação tecnológica mais crítica e construtiva, que preza pela formação participativa do cidadão, o ponto de partida é entender todas as facetas da tecnologia para, a partir de então, buscar também compreender como nossos estudantes entendem, se relacionam e o que esperam da mesma.

Assim, na busca por trazer subsídios para gerar futuras discussões de novas políticas públicas educacionais, este artigo se propõem a desmistificar as concepções de tecnologia, e descobrir quais delas se fazem mais presentes nas opiniões de graduandos das mais diferentes áreas. E, para que este objetivo se cumpra, a revisão bibliográfica a seguir abrirá as portas para que uma pesquisa de opinião pública, aplicada em diferentes regiões do Estado de São Paulo, seja explicitada e analisada no tocante ao que realmente venha a ser a tecnologia para a amostra de graduandos entrevistados.

\section{As diversas formas de se compreender a tecnologia}

É preciso lembrar que a história do homem iniciou-se juntamente com a história das técnicas, com a utilização de objetos que foram transformados em instrumentos diferenciados, fazendo nascer, assim, a tecnologia, que evoluiu em complexidade juntamente com o processo de construção das sociedades humanas (VERASZTO, 2004).

Tanto a palavra técnica como a palavra tecnologia têm origem comum no termo grego techné (ou tékhnê), que, a princípio, estava muito mais relacionado com a alteração do mundo de forma prática do que com sua compreensão. Inicialmente, era um processo onde a contemplação científica praticamente não exercia influências. Na técnica, a questão principal era tida, pelos gregos, no como transformar, como modificar. Uma preocupação oriunda do significado original do termo techné como sendo uma das variáveis do verbo teuchô ou tictein, que significa fabricar, produzir, construir, dar à luz. Verbo cujo sentido primordial vem de Homero e que deu origem ao teuchos, substantivo que significa ferramenta, instrumento (VERASZTO, 2009). Assim, a palavra tecnologia provém da junção da tékhné com o logus. O tecno, que é saber fazer, somado à razão da logia, deu origem à tecnologia, que passou a significar a razão do saber fazer, ou, em outras palavras, o estudo da técnica, o estudo da própria atividade do modificar, do transformar, do agir (SIMON et al., 2004a).

Mesmo sendo um ponto de vista singular, é a maneira como o termo tecnologia foi concebido. A partir de então, a tecnologia foi estudada, interpretada e analisada, ao longo dos anos, de formas variadas, dando indícios de que pode ser estruturada em um campo próprio do conhecimento, capaz de englobar diferentes aspectos a partir dos quais uma sociedade se desenvolve e se organiza (VERASZTO, 2004).

Vargas (2001) afirma que a tecnologia exige, por parte dos seus agentes, um profundo conhecimento de como e por que seus objetivos são alcançados, além de pedir uma reformulação de estruturas e metas do ambiente onde se instala. Seguindo esta linha de raciocínio, Veraszto et al. (2008) afirmam que a tecnologia pode ser vista como um conjunto de atividades humanas associadas a um intrincado conjunto de símbolos, maquinários e instrumentos que visam a planificação e o desenvolvimento de artefatos, sistemas ou serviços, segundo métodos e processos derivados da ciência moderna, impregnados por valores e códigos de cunho moral, político e econômico, e ético. 
Com esta breve introdução à gênese do termo tecnologia, agora é importante apontar e sintetizar concepções anacrônicas e distintas empregadas para a mesma. Todavia, também é importante que fique claro que não se tratam de teorias bem articuladas, mas, sim, de imagens populares arraigadas no público de uma maneira geral, e presentes com frequência na mídia, em divulgações científicas, em documentos e legislações educacionais, assim como, também, na opinião de um grande número de experts responsáveis pelo processo de produção e desenvolvimento tecnológico. É possível constatar essa diversidade no trabalho publicado por Veraszto et al. (2008), cujas principais ideias estão resumidas no Quadro 1.

\section{Procedimentos metodológicos da pesquisa}

Esse trabalho caracteriza-se por ser uma pesquisa quantitativa. Por isso, tem como vantagem o fato de permitir levantar informações com confiabilidade estatística, por se tratar de um estudo descritivo que busca relações de causalidade entre diferentes agrupamentos de variáveis para a resolução do problema da pesquisa.

Assim, a opção pela abordagem estatística apoia-se na afirmação de Hair Jr. et al. (2005) de que o modelo de equações estruturais provê um método direto para lidar, simultaneamente, com múltiplos relacionamentos de dependência com eficiência estatística, explorando-os de maneira aprofundada. Mesmo esse trabalho se limitando a apresentar um recorte da pesquisa, que é o de analisar as concepções de tecnologia presentes em graduandos, o método escolhido é bastante apropriado, tendo em vista que, para a análise global do modelo, é gerada uma análise confirmatória que permite a representação de conceitos não observáveis, verificando, inclusive, possíveis erros de mensuração ocorridos durante o processo estatístico.

\section{Hipótese inicial}

Esta pesquisa tomou como base a elaboração e teste de modelos causais, buscando relacionar as concepções $(\mathrm{CON})$ que os indivíduos têm acerca da tecnologia, suas atitudes e expectativas frente ao desenvolvimento tecnológico (ATI) e as influências da dimensão social (DSO), conforme apresentado na Figura 1.

Figura 1. Relação Estrutural do Modelo DSO1: Influência da Sociedade

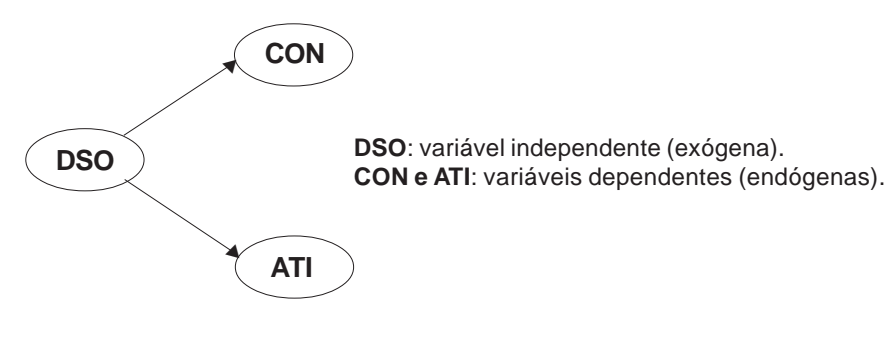

Fonte: Veraszto (2009). 
Concepções de tecnologia de graduandos ...

Quadro 1. Resumo referenciado das diferentes concepções acerca da tecnologia

\begin{tabular}{|c|c|c|c|}
\hline $\mathbf{N}^{\circ}$ & $\begin{array}{l}\text { Concepção de } \\
\text { tecnologia }\end{array}$ & Compreensão do conceito & Referências \\
\hline 1 & Intelectualista & $\begin{array}{l}\text { Compreende a tecnologia como um } \\
\text { conhecimento prático derivado diretamente } \\
\text { do desenvolvimento do conhecimento } \\
\text { científico através de processos } \\
\text { progressivos e acumulativos }\end{array}$ & $\begin{array}{l}\text { Acevedo, 1998; Acevedo Díaz, 1997, } \\
\text { 2001; González García; López Cerezo; } \\
\text { Luján López, 2000; Layton, 1988; } \\
\text { Osorio M., } 2002 .\end{array}$ \\
\hline 2 & Utilitarista & $\begin{array}{l}\text { Considera a tecnologia como sendo } \\
\text { sinônimo de técnica. Ou seja, o processo } \\
\text { envolvido em sua elaboração não tem } \\
\text { relação com a tecnologia, apenas a sua } \\
\text { finalidade e utilização. }\end{array}$ & $\begin{array}{l}\text { Acevedo Díaz, 1997; Agazzi, 1997; } \\
\text { Bunge, 1972, } 1986 \text { apud Osorio M, } \\
\text { 2002; Veraszto, } 2004 .\end{array}$ \\
\hline 3 & $\begin{array}{l}\text { Tecnologia como } \\
\text { sinônimo de } \\
\text { ciência }\end{array}$ & $\begin{array}{l}\text { Encara a tecnologia como sendo Ciência } \\
\text { Natural e Matemática, com as mesmas } \\
\text { lógicas e mesmas formas de produção e } \\
\text { concepção. }\end{array}$ & $\begin{array}{l}\text { Acevedo Díaz, 1997, 2001; Hilst, 1994; } \\
\text { Martín Gordillo, 2001; Sancho, 1998; } \\
\text { Silva; Barros Filho, 2001; Valdés et al., } \\
2002 .\end{array}$ \\
\hline 4 & $\begin{array}{l}\text { Instrumentalista } \\
\text { (ou artefatual) }\end{array}$ & $\begin{array}{l}\text { Considera a tecnologia como sendo } \\
\text { simples ferramentas, artefatos ou } \\
\text { produtos, geralmente sofisticados. }\end{array}$ & $\begin{array}{l}\text { Acevedo Díaz, 1997, 2001; González } \\
\text { García; López Cerezo; Luján López, } \\
\text { 2000; Osorio M., 2002; Lion, 1997; } \\
\text { Pacey, 1983; Silva et al., 2000; Silva; } \\
\text { Barros Filho, 2001; Veraszto, } 2004 .\end{array}$ \\
\hline 5 & $\begin{array}{l}\text { Neutralidade } \\
\text { tecnológica }\end{array}$ & $\begin{array}{l}\text { Compreende que a tecnologia não é boa } \\
\text { nem má. Seu uso é que pode ser } \\
\text { inadequado, não o artefato em si. }\end{array}$ & $\begin{array}{l}\text { Cáceres Gómez, 2001; Dagnino, 2007; } \\
\text { Durán Carrera, 2001; González } \\
\text { García; López Cerezo; Luján López, } \\
\text { 2000; Osorio M., 2002; Winner, } 2008 .\end{array}$ \\
\hline 6 & $\begin{array}{l}\text { Determinismo } \\
\text { tecnológico } \\
\text { (tecnologia } \\
\text { autônoma) }\end{array}$ & $\begin{array}{l}\text { Considera a tecnologia como sendo } \\
\text { autônoma, autoevolutiva, seguindo } \\
\text { naturalmente sua própria inércia e lógica } \\
\text { de evolução, desprovida do controle dos } \\
\text { seres humanos. }\end{array}$ & $\begin{array}{l}\text { Cáceres Gómez, 2001; Dagnino, 2007; } \\
\text { Durán Carrera, 2001; González } \\
\text { García; López Cerezo; Luján López, } \\
\text { 2000; Osorio M., } 2002 .\end{array}$ \\
\hline 7 & $\begin{array}{l}\text { Universalidade } \\
\text { da tecnologia }\end{array}$ & $\begin{array}{l}\text { Entende a tecnologia como sendo algo } \\
\text { universal; um mesmo produto, serviço ou } \\
\text { artefato poderia surgir em qualquer local e, } \\
\text { consequentemente, ser útil em qualquer } \\
\text { contexto. }\end{array}$ & $\begin{array}{l}\text { Cáceres Gómez, 2001; Martín } \\
\text { Gordillo; González Galbarte, } 2002 .\end{array}$ \\
\hline 8 & $\begin{array}{l}\text { Pessimismo } \\
\text { tecnológico }\end{array}$ & $\begin{array}{l}\text { Considera a tecnologia como algo nocivo e } \\
\text { pernicioso para a sustentabilidade do } \\
\text { planeta, responsável pela degradação do } \\
\text { meio e pelo alargamento das } \\
\text { desigualdades sociais. }\end{array}$ & $\begin{array}{l}\text { Agazzi, 1997; Barnett; Morse, 1977; } \\
\text { Carranza, 2001; Colombo; Bazzo, } \\
\text { 2002; Corazza, 1996, 2004, 2005; } \\
\text { Meadows et al., 1972. }\end{array}$ \\
\hline 9 & $\begin{array}{l}\text { Otimismo } \\
\text { tecnológico }\end{array}$ & $\begin{array}{l}\text { Compreende a tecnologia como portadora } \\
\text { de mecanismos capazes de assegurar o } \\
\text { desenvolvimento sustentável e sanar } \\
\text { problemas ambientais, sociais e materiais. }\end{array}$ & $\begin{array}{l}\text { Agazzi, 1997; Andrade, 2004; Carranza, } \\
\text { 2001; Foray; Grübler, 1996; Freeman, } \\
\text { 1996; Herrera, 1994; World } \\
\text { Commission on Environment and } \\
\text { Development, } 1987 .\end{array}$ \\
\hline 10 & Sociossistema & $\begin{array}{l}\text { Considera que a tecnologia é determinada } \\
\text { pela interação de diferentes grupos através } \\
\text { de relações sociais, políticas, econômicas, } \\
\text { ambientais, culturais, entre outras. }\end{array}$ & $\begin{array}{l}\text { González García; López Cerezo; Luján } \\
\text { López, 2000; Grinspun, 2001; Osorio } \\
\text { M, 2002; Pacey, 1983; Sancho, 1998; } \\
\text { Silva et al., } 2000 .\end{array}$ \\
\hline
\end{tabular}

Fonte: elaborado pelos autores a partir de Veraszto (2009). 
De uma maneira geral, este modelo pode ser traduzido na seguinte hipótese: A dimensão social influencia as concepções de tecnologia dos indivíduos nela inseridos, proporcionando atitudes favoráveis frente a um desenvolvimento tecnológico sustentável.

A partir destas relações, todas as variações foram testadas (sendo duas delas obtidas pela troca de constructos de lugar no modelo, e as três restantes obtidas pelas suas respectivas relações inversas), e foi verificada a adequação da acima apresentada, ou seja, os dados da pesquisa apontaram que, no entendimento dos alunos de graduação pesquisados, setores específicos da sociedade, como governo e instituições de ensino e pesquisa, influenciam diretamente no processo de desenvolvimento tecnológico, bem como são as bases das concepções e das atitudes refletidas pela sociedade.

Mesmo não generalizando a pesquisa, também ficou evidenciado, como será mostrado a seguir, que os pesquisados sentem-se prontos e aptos para participarem de uma sociedade que seja capaz de adotar um modelo mais democrático de decisões e escolhas tecnológicas.

\section{Amostragem e coleta de dados}

Com isto posto e partindo do referencial teórico apresentado anteriormente, uma pesquisa foi desenvolvida na Universidade Estadual de Campinas (VERASZTO, 2009), com o intuito de trazer, também, um referencial para melhor se entenderem as concepções de tecnologia de graduandos de diferentes regiões do Estado de São Paulo.

Nesta pesquisa foi adotada a técnica de corte transversal, que é amplamente utilizada e que tem como característica básica a coleta de informações de todas as variáveis de uma maneira simultânea. A vantagem deste método é a de permitir a obtenção de uma fotografia das variáveis de interesse do estudo em um dado momento no tempo, enfatizando a seleção de uma amostra significativa e representativa da população-alvo (MALHOTRA, 2001).

As instituições que representaram a amostra foram selecionadas considerando-se os critérios de serem universidades de natureza pública e privada. A universidade pública escolhida, localizada no município de Campinas, SP, tem alunos das mais diferentes regiões do Estado de São Paulo, assim como outras três instituições particulares: uma universidade e uma faculdade do município de São Paulo, SP, e uma faculdade do município de Campinas, SP. As outras duas faculdades selecionadas são do interior, e recebem alunos de diferentes regiões do interior do Estado, e, também, foram escolhidas em função do pesquisador já ter atuado por um grande período em uma delas e estar iniciando atividades em outra. A diversidade de cursos que as quatro instituições apresentam também foi fator decidivo para suas escolhas.

A coleta de dados foi feita com mil e três alunos de diferentes cursos, e os questionários foram, em sua grande maioria, passados antes de iniciarem as aulas. Foram selecionados alunos dos cursos: Engenharia Ambiental, Ciência da Computação, Nutrição, Psicologia, Administração, Engenharia Elétrica, Engenharia da Produção, Física, Matemática, Tecnologia em Gestão Ambiental, Pedagogia.

\section{Elaboração de indicadores de concepções de tecnologia}

Toda a revisão literária, resumida, em sua maior parte, no Quadro 1, passou por um processo sistemático de análise e classificação para a construção do instrumento de pesquisa. 
Concepções de tecnologia de graduandos ...

A partir de artigos, livros, documentos nacionais e internacionais, este trabalho buscou coletar informações fornecidas em cada texto, classificando e categorizando todas as concepções existentes sobre tecnologia. Foi a partir dessas categorizações que os indicadores do trabalho foram desenvolvidos, agrupando as variáveis para, posteriormente, transformá-las nas assertivas finais apresentadas no Quadro 2 após refinamento, análise semântica e estrutural elaboradas por oito especialistas (dentre os quais, quatro são doutores, três são doutorandos em educação e ciências sociais, e um outro, mestre em educação, sendo, dos oito, sete especialistas em pesquisas quantitativas) e pré-teste.

Quadro 2. Indicadores propostos para concepções de tecnologia

\begin{tabular}{|c|l|}
\hline $\begin{array}{c}\text { Concepções } \\
\text { de tecnologia }\end{array}$ & \\
\hline $\mathbf{1}$ & CON 01: Tecnologia é aplicação de leis, teorias e modelos da Ciência. \\
\hline $\mathbf{2}$ & CON 02: A tecnologia não precisa de teorias; precisa apenas ser prática e eficiente. \\
\hline $\mathbf{3}$ & CON 03: A tecnologia explica o mundo à nossa volta. \\
\hline $\mathbf{4}$ & $\begin{array}{l}\text { CON 04: Hoje, há tecnologias que podem ser adquiridas por um preço acessível para } \\
\text { muitos, tais como: celulares, aparelhos de som, microcomputadores etc. }\end{array}$ \\
\hline $\mathbf{4}$ & $\begin{array}{l}\text { CON 05: Tecnologias são ferramentas (ou artefatos) construídas para auxiliar o homem na } \\
\text { resolução de diferentes tipos de tarefas. }\end{array}$ \\
\hline $\mathbf{5}$ & CON 06: A tecnologia não sofre influências da sociedade. \\
\hline $\mathbf{5}$ & CON 07: O uso que fazemos da tecnologia é que determina se ela é boa ou má. \\
\hline $\mathbf{6}$ & $\begin{array}{l}\text { CON 08: O inventor perde o controle sobre a invenção uma vez que esta é disponibilizada } \\
\text { para 0 público. }\end{array}$ \\
\hline $\mathbf{7}$ & CON 09: Uma nova descoberta tecnológica pode ser útil em qualquer lugar do planeta. \\
\hline $\mathbf{8}$ & CON 10: A tecnologia pode acabar com o planeta. \\
\hline $\mathbf{8}$ & CON 11: A tecnologia aumenta as desigualdades socioeconômicas. \\
\hline $\mathbf{8}$ & CON 12: A tecnologia ameaça a privacidade das pessoas. \\
\hline $\mathbf{9}$ & $\begin{array}{l}\text { CON 13: Os benefícios proporcionados pelo desenvolvimento tecnológico são maiores que } \\
\text { seus efeitos negativos. }\end{array}$ \\
\hline $\mathbf{9}$ & CON 14: A engenharia genética pode contribuir para a cura de doenças. \\
\hline CON 15: Diferentes grupos de interesses determinam a produção tecnológica a partir de \\
\hline relações sociais, políticas, econômicas, ambientais, culturais etc.
\end{tabular}

Fonte: elaborado pelos autores a partir de Veraszto (2009).

\section{Análise dos dados e resultados obtidos}

Mesmo nos atentando somente para o constructo que trata das concepções de tecnologia, abaixo seguem os resultados do trabalho para a validação e ajuste do modelo. Esta apresentação breve é importante para mostrar a confiabilidade dos resutaldos e robustez do método adotado na pesquisa. 


\section{Avaliação individual dos construtos}

Os dados registrados no questionário impresso foram digitados em uma planilha Excel e processados pelo SPSS ${ }^{\circledR} 13.0^{5}$ para verificação da unidimensionalidade e confiabilidade dos construtos, e pelo LISREL ${ }^{\circledR} 8.54^{6}$, para ajuste do modelo, pois dispõe de recursos adequados aos propósitos desta pesquisa (HAYDUK, 1987; BOLLEN; LONG, 1993; BYRNE, 1998; MARUYAMA, 1998; JÖRESKOG; SÖBOM, 1993, 2001, 2003; HAIR JR. et al., 2005; HANCOCK; MUELLER, 2006). A codificação foi feita com a linguagem de comando SIMPLIS ${ }^{\mathrm{TM}}$, disponível no sistema, que viabilizou a estimação dos parâmetros do modelo e a apuração das medidas segundo diferentes métodos.

\section{Validação do modelo}

A partir da avaliação individual de cada construto, foi possível realizar a validação do modelo de medidas aplicando-se a Análise Fatorial Confirmatória (Confirmatory Factor Analysis, CFA). Essa técnica tem o propósito de testar a hipótese de ajuste dos dados empíricos a um modelo teórico, onde uma estrutura de relação é imposta e confirmada pela análise. Além disso, a validação do modelo foi realizada através de sucessivos ajustes (JÖRESKOG; SÖRBOM, 1993, 2003).

\section{Unidimensionalidade dos construtos}

Este critério consistiu em verificar se os indicadores estabelecidos representavam, de fato, um único construto, posto que a unidimensionalidade é uma premissa para a confiabilidade do construto. Para a constatação da unidimensionalidade foi observado que cada valor da matriz de resíduos normalizados dos construtos eram pequenos e menores que 2,58 , em módulo, a um nível de significância de 1\%. A unidimensionalidade que é verificada quando se tem apenas $5 \%$ dos resíduos normalizados excedendo o valor absoluto de referência de 2,58 (acima de 2,58 ou abaixo de -2,58), foi constatada para todos os construtos apresentando resíduos compatíveis com o valor de referência (-2,565 para o menor resíduo e 2,972 para o maior). Foi feita também uma análise minuciosa dos resíduos padronizados de todas as dimensões, e verificou-se que a quantidade geral de resíduos que ultrapassa o valor de 2,58 é muito baixa (cerca de $2,4 \%$ ).

\footnotetext{
${ }^{5}$ SPSS é um software estatístico profissional destinado à análise e tratamento de dados. Possui módulos que permitem desde a análise descritiva de variáveis até as técnicas multivariadas. Disponível em: <http:// www.spss.com.br/>. Acesso em: 13 ago. 2013.

${ }^{6}$ LISREL é um software estatístico profissional destinado, sobretudo, à técnica de Modelagem de Equações Estruturais. Disponível em: <http://www.ssicentral.com/lisrel/>. Acesso em: 13 ago. 2013.
} 


\section{Confiabilidade dos construtos (CC)}

A confiabilidade é uma medida da consistência interna dos indicadores do construto e da adequacidade das escalas para medi-lo. Um valor comumente usado para aceitação da confiabilidade é 0,70 (HAIR JR. et al., 2005). Utilizando o LISREL ${ }^{\circledR}$, o resultado para o modelo inicial foi de 0,704161 , acima do padrão estabelecido, mostrando que a escala validada não apresentou vieses consideráveis e, portanto é plenamente aceitável. Além do mais, os valores obtidos para o índice de Confiabilidade dos Construtos sinalizaram que as medidas realizadas são bastante adequadas, confirmando a utilização da escala de concepções de tecnologia.

\section{Concepções de tecnologia: indicadores empíricos}

A pesquisa ainda contou com o ajuste e avaliação de todas as variações do modelo inicial. Contudo, como o propósito desta pesquisa é o de avaliar somente o construto referente às concepções de tecnologia, cabe aqui ressaltar que as mesmas foram originadas da análise confirmatória do modelo integrado que apresentou indicadores de ajuste bastante adequado se comparado com a literatura, conforme mostra a Tabela 1.

Tabela 1. Comparação das Medidas de Ajustamento do Modelo Original com o Método de Máxima Verossimilhança (MLE)

\begin{tabular}{|c|c|c|}
\hline $\begin{array}{l}\text { Indicadores principais } \\
\text { do ajuste do modelo }\end{array}$ & $\begin{array}{c}\text { Valores obtidos com o } \\
\text { método MLE para o } \\
\text { modelo inicial }\end{array}$ & $\begin{array}{l}\text { Valores de } \\
\text { referência }\end{array}$ \\
\hline Graus de liberdade & 144 & $x$ \\
\hline Chi-quadrado & 218.865 & $\mathrm{X}$ \\
\hline Chi-quadrado Ponderado $(\div 2 / G L)$ & 1,52 & Abaixo de 5,00 \\
\hline Raiz Quadrada do Erro de Aproximação (Root Mean Square Error & 0.0308 & Abaixo de 0,08 \\
\hline of Approximation -RMSEA) & 0.817 & Acima de 0,90 \\
\hline Índice de ajuste padronizado (Normed Fit Index - NFI) & 0.913 & Acima de 0,90 \\
\hline Índice de Ajuste Não Padronizado (Non-Normed Fit Index - NNFI) & 0.927 & Acima de 0,90 \\
\hline Índice de Ajuste Comparativo (Comparative Fit Index - CFI) & 0.962 & Acima de 0,90 \\
\hline Índice de Aderência (Goodness of Fit Index - GFI) & 0.95 & Acima de 0,90 \\
\hline
\end{tabular}

Fonte: elaborado pelo autor. Valores de referência segundo Hair Jr. et al. (2005).

Estas medidas foram utilizadas como forma de avaliar cada construto e o modelo integrado, pois um modelo ajustado funciona como referência para a confirmação da validade dos construtos, em nível individual, e dos relacionamentos entre eles, no que diz respeito ao modelo estrutural completo. Vários indicadores foram excluídos na tentativa de se obter o melhor modelo ajustado. Dos 15 indicadores de concepções de tecnologia, restaram 4, conforme aponta Tabela 2. Estes indicadores resultaram da aplicação da técnica Maximum Likelibood Estimation (MLE).

Para não alongar a discussão a respeito do modelo integrado, basta concluir que a hipótese de pesquisa inicial foi confirmada, o que corrobora para a análise das concepções de tecnologia dos graduandos pesquisados. 
Veraszto, E. V. et al.

Tabela 2. Frequência de resposta dos estudantes aos indicadores propostos

\begin{tabular}{|c|c|c|c|c|c|c|c|c|c|}
\hline Indicador & Assertivas & $\begin{array}{l}\text { CP } \\
(1)\end{array}$ & $\begin{array}{l}C \\
(2)\end{array}$ & $\begin{array}{c}1 \\
(3)\end{array}$ & $\begin{array}{l}D \\
(4)\end{array}$ & $\begin{array}{l}\text { DP } \\
(5)\end{array}$ & Média & Mediana & $\begin{array}{l}\text { Desvio } \\
\text { padrão }\end{array}$ \\
\hline CON 03 & A tecnologia explica o mundo à nossa volta. & 149 & 283 & 79 & 77 & 12 & 2.2000 & 2 & 1.01738 \\
\hline CON 01 & $\begin{array}{l}\text { Tecnologia é aplicação de leis, teorias e } \\
\text { modelos da Ciência. }\end{array}$ & 106 & 274 & 95 & 111 & 14 & 2.4217 & 2 & 1.05311 \\
\hline CON 05 & $\begin{array}{l}\text { Tecnologias são ferramentas (ou artefatos) } \\
\text { construídas para auxiliar o homem na } \\
\text { resolução de diferentes tipos de tarefas. }\end{array}$ & 255 & 306 & 24 & 14 & 1 & 1.6667 & 2 & 0.68044 \\
\hline CON 07 & $\begin{array}{l}\text { O uso que fazemos da tecnologia é que } \\
\text { determina se ela é boa ou má. }\end{array}$ & 198 & 261 & 50 & 72 & 19 & 2.0883 & 2 & 1.08281 \\
\hline
\end{tabular}

Fonte: Veraszto (2009).

\section{Análise de frequência de respostas aos indicadores}

$\mathrm{Na}$ tentativa de compreender o posicionamento dos participantes acerca dos indicadores, realizou-se a análise de frequência dos dados. A Tabela 2 apresenta a quantidade de respostas por quesito, bem como a média, a mediana e o respectivo desvio padrão, obtidos após aplicação de valores para transformação métrica da escala Likert utilizada na pesquisa.

\section{CON 03: A tecnologia explica o mundo à nossa volta}

Esta reflete a perpetuação que um dos pontos de vista clássicos do senso comum, o da tecnologia como sinônimo de ciência, ainda está presente em nossa sociedade. O fato de não se conseguir estabelecer distinção entre tecnologia e ciência é opinião comum manifestada por muitas pessoas, conforme já apontou a revisão da literatura e foi comprovado pelos valores médio e mediano que esta assertiva apresentou.

\section{CON 01: Tecnologia é aplicação de leis, teorias e modelos da Ciência}

Da mesma maneira que na assertiva anterior, os valores das medidas de posição para a assertiva A6 também mostram que os graduandos pesquisados apresentam outra visão clássica do senso comum: o ponto de vista intelectualista da tecnologia. Esta visão complementa a anterior, dando margem para a interpretação de que os pesquisados entendem que a tecnologia deriva, única e exclusivamente, da ciência, inclusive na escolha e aplicação de seus métodos.

É um ponto de vista clássico, existente, pelo menos, desde o final do século XIX, onde a tecnologia é vista como sendo um conhecimento prático derivado diretamente do conhecimento teórico científico. Em outras palavras, seria como afirmar que o conhecimento teórico científico implica necessariamente obtenção de novas tecnologias. Contudo, a ciência pura não tem relação nenhuma, pelo menos a princípio, com a tecnologia. Todas as teorias antecedem as tecnologias, de forma que não existe tecnologia sem teoria, mas o inverso pode acontecer: é concebível a existência de teorias sem tecnologias (GONZÁLEZ GARCÍA; LÓPEZ CEREZO; LUJÁN LÓPEZ, 2000). 
É um modelo hierárquico e um ponto de vista que perdura e faz com que muitas pessoas acreditem que a tecnologia é subordinada às ciências, chegando até mesmo a defini-la como a ciência da aplicação do conhecimento para fins práticos. Como o "explicar" e o "teorizar" são, até hoje, envoltos em uma atmosfera mais coerente e estrutural; a ciência sempre teve o status quo de campo do saber de "primeira classe" enquanto a tecnologia ficou restrita a um "nicho" de aplicação e de consequência daquela (ACEVEDO, 1998; LAYTON, 1988).

É uma concepção que comprova que os alunos não distinguem ciência de tecnologia.

\section{CON 05: Tecnologias são ferramentas (ou artefatos) construídas para auxiliar o homem na resolução de diferentes tipos de tarefas}

Outra visão do senso comum também esteve presente nesta pesquisa como peçachave para o entendimento da concepção de tecnologia dos graduandos pesquisados. A noção de tecnologia instrumentalista (ou artefactual), conforme aponta a literatura mencionada anteriormente, é bastante normal e reflete, de forma direta, a ideia de que a tecnologia é vista como uma simples ferramenta, um produto, um artefato. E os valores médio e mediano apontam que os indivíduos pesquisados são passíveis de sustentar que não existe uma diferença essencial entre os utensílios de pedra da antiguidade e os modernos artefatos tecnológicos, conforme afirmam González García, López Cerezo e Luján López (2000). É um ponto de vista que gera grandes confusões por acreditar que a produção tecnológica consiste apenas nos equipamentos gerados a partir da mesma. Isto pode fazer com que se acredite que basta saber ligar o equipamento, conhecer as siglas que os fabricantes criam, e utilizá-lo, para ser expert em tecnologia. Há ainda uma certa "aura" de poder pelo uso das inovações tecnológicas, não apenas entre países, mas, também, entre pessoas comuns: comprar algum equipamento novo com mais funções e com mais recursos, que efetivamente não serão usados, pode satisfazer certos impulsos "fetichistas" de consumo e de exercício de uma supremacia, frente aos seus pares (SILVA et al., 1999; SILVA; BARROS FILHO, 2001).

\section{CON 07: O uso que fazemos da tecnologia é que determina se ela é boa ou má}

Essa concepção aponta que os estudantes de graduação pesquisados consideram que a tecnologia é neutra. Esse ponto de vista reflete que não existe uma reflexão apropriada em relação às concepções tecnológicas e ao seu processo de desenvolvimento, ou seja, a tecnologia não reflete as intenções nem tampouco os interesses dos grupos desenvolvedores.

A ideia da neutralidade do conhecimento científico tem sua origem nas próprias condições de seu surgimento como tal, a partir do século XV, como uma oposição ao conhecimento (ou pensamento) religioso. Para muitos, ciência e religião compartilhariam o mesmo objetivo: a verdade. A diferença seria que a ciência admite só a autoridade da razão e da experiência.

Se considerada como independente de qualquer sistema político ou social, a tecnologia pode ser transferida de um país a outro sem dificuldade alguma. Essa visão reducionista da tecnologia impede sua análise crítica e ignora as intenções e interesses sociais, econômicos e políticos daqueles que a idealizam, financiam e controlam. Sabemos que a tecnologia não é 
Veraszto, E. V. et al.

neutra; um artefato aparentemente inócuo pode estar carregado de interesses políticos (e/ou outros) (WINNER, 2008). A tecnologia, longe de ser neutra, reflete os planos, propósitos e valores da nossa sociedade. Contudo, a presença deste indicador, na opinião dos alunos pesquisados, reflete que esta visão de não-neutralidade está distante da realidade e da concepção de tecnologia por eles defendida.

\section{Considerações finais e as implicações para a educação}

Com os indicadores acima apresentados, foi possível inferir que os graduandos pesquisados deixam transparecer três aspectos básicos que comumente aparecem como sendo indicadores do senso comum da interpretação da tecnologia. De forma mais geral, pode-se dizer que a pesquisa revelou que a tecnologia é entendida, pela grande maioria dos graduandos, como sendo intelectualista e sinônimo de ciência, bem como sendo instrumentalista e neutra.

Assim, a pesquisa mostrou que entender a tecnologia como um conhecimento prático derivado do conhecimento teórico científico, ou até mesmo confundi-la com ciência é um forte indicador.

Isso significa que uma reflexão mais profunda acerca do processo de produção tecnológico e todos seus reais motivos de concepção não estão presentes na maioria dos pesquisados. A concepção instrumentalista auxilia nessa conclusão de maneira significativa. Se o processo não é considerado, resta somente o produto. E a utilização deste produto é de responsabilidade única e exclusiva de quem o adquire, não refletindo, assim, os interesses daqueles que o desenvolve. Essa colocação é sustentada pela visão de tecnologia neutra também presente no modelo.

De uma forma geral, mesmo o conceito de tecnologia presente é clássico e um tanto quanto limitado. Assim, dada a constatação de que as concepções sobre tecnologia, dos sujeitos da amostra, são muito primitivas, o que se pode fazer para mudá-las?

Algumas ações pedagógicas podem ser engendradas para uma melhoria conceitual dos nossos alunos.

Assim, pode-se dizer que os dados aqui obtidos são importantes, tendo em vista que é fundamental que tanto professores, como gestores educacionais conheçam as concepções dos alunos para, a partir de então, direcionar atividades de ensino ou elaboração de planos curriculares capazes de formar um cidadão tecnologicamente crítico e participante.

Desta forma, como sugestão para futuras políticas públicas de educação, fica a ideia de que a gestão de processos educativos possa, antes de tudo, levantar e explicitar o conhecimento dos alunos antes do desenvolvimento e aplicação de atividades educativas.

Ao se pensar em estratégias educacionais, também é importante considerar que, quando se constata que um termo tão amplamente utilizado carece de consenso, é importante se pensar em estratégias capazes de desencadear processos de desequilíbrios cognitivos, através do questionamento dessas concepções e/ou da colocação de problemas que exijam a tomada de decisões, numa perspectiva de simulação, em sala de aula, de situações reais, que sejam capazes de fomentar debates e discussões entre os alunos. Assim, o desencadeamento de reflexões e conflitos cognitivos pode ser colocado em prática na sala de aula, tendo o professor como instigador e desafiador do processo educativo. Ao se trazerem as ideias dos alunos 
para uma discussão coletiva, criando um clima de investigação, se torna possível fomentar a busca e a sistematização de informações e experiências individuais, gerando novas necessidades de busca de conhecimentos e informações coletivas. Essa busca pelo trabalho coletivo faz com que a passividade produzida pelo excesso de aulas expositivas migre para um dinamismo apoiado pelas novas e atuais diretrizes curriculares.

Estratégias de ensino assim elaboradas podem vir a permitir e incentivar que os alunos desenvolvam seus próprios métodos como uma alternativa para o excesso de ações pedagógicas "pasteurizadas" em apostilas, regras e soluções de problemas descontextualizados. Desta maneira, se torna possível que os alunos desenvolvam mais senso crítico do conhecimento, estabelecendo relações que não tendem a priorizar a memória como elemento central.

Respeitando os limites impostos pela amostra, os resultados da pesquisa, ao constatarem um conceito de tecnologia limitado e ultrapassado, fazem com que seja possível inferir que mudanças curriculares e propostas de melhoria e adequação são necessárias, mas não suficientes para provocarem alterações significativas na formação de novos profissionais.

É preciso um investimento na alteração dos processos tradicionais adotados em sala de aula através da adequação da metodologia de ensino dos professores, pois, se os nossos alunos interpretam a tecnologia e suas relações como aspectos supérfluos, é fato que pode-se ter melhor exposição sobre esse assunto por parte de um professor. E isso só será atingido se métodos, ideologias e formas de se fazer política pública em educação sofrerem alterações de base, ao se considerar que os tempos são outros e que a sociedade exige mais dinamismo e contextualização nos processos educacionais.

\section{Referências}

ABREU, R. G. Tecnologia e ensino de ciências: recontextualização no novo ensino médio. [S.l.: s.n.], 2008. Disponível em: <http://nutes2.nutes.ufrj.br/coordenacao/ textosapoio/tap-rt01-15.pdf >. Acesso em: 26 abr. 2010.

ACEVEDO, G. D. R. Ciencia, tecnología y sociedad: una mirada desde la educación en tecnología. Revista Iberoamericana de Educación, Madrid, n. 18, p. 107-143, 1998.

ACEVEDO DÍAZ, J. A. Cambiando la práctica docente en la enseñanza de las ciencias a través de CTS. [S. 1.]: OEI, 1996. Disponível em: <http://www.campusoei.org/salactsi/acevedo2.htm>. Acesso em: 17 ago. 2009.

Una breve revisión de las creencias CTS de los estudiantes. [S. 1.]: OEI, 2001. Disponível em: <http://www.oei.es/salactsi/acevedo.htm>. Acesso em: 19 jan. 2010.

. ¿Qué puede aportar la historia de la tecnología a la educación CTS? [S. 1.]: OEI, 1997. Disponível em: <http://www.oei.es/salactsi/acevedo3.htm>. Acesso em: 8 dez. 2009. 
Veraszto, E. V. et al.

ADRIÃO, M. Padrões tecnológicos e a produção social da tecnologia. Revista Eletrônica de Sistemas de Informação, Campo Largo, v. 7, n. 2, p. 1-19, 2008. Disponível em: $<$ http://revistas.facecla.com.br/index.php/reinfo/article/view/74>. Acesso em: 12 ago. 2013.

AGAZZI, E. E1 impacto de la tecnología. [S. 1.: s.n.], 1997. Disponível em: <http://www.argumentos.us.es/numero1/agazzi.htm>. Acesso em: 7 jun. 2009.

ANDRADE, T. Inovação tecnológica e meio ambiente: a construção de novos enfoques. Ambiente \& Sociedade, Campinas, v. 7, n. 1, p. 89-105, jan./jun. 2004.

AULER, D.; DELIZOICOV, D. Ciência-tecnologia-sociedade: relações estabelecidas por professores de ciências. Revista Electrónica de Enseñanza de las Ciencias, Vigo, v. 5, n. 2, p. 337-355, 2006.

BARNETT, H. J.; MORSE, C. Scarcity and growth: the economics of natural resources availability. Baltimore: John Hopkins Press, 1977.

BARROS FILHO, J. et al. Percepciones de los estudiantes de secundaria acerca de la tecnología y sus relaciones con la escuela. Icono 14: revista de comunicación, educación y TIC, Madrid, n. 3, p. 711-720, 2009. (Especial Actas n. A3: I Congreso Internacional Ciudades Creatrivas).

. Percepções de alunos do ensino médio a respeito de tecnologias e suas relações com a escola. UDESC Virtu@1 Online: revista do centro de educação a distância, Florianópolis, v. 2, n. 1, p. 14-26, 2010.

BOLLEN, K. A.; LONG, J. S. (Ed.). Testing structural equation models. Newbury Park: Sage, 1993.

BRASIL. Lei $\mathbf{n}^{\circ}$ 9.394, de 20 de dezembro de 1996. Estabelece as diretrizes e bases da educação nacional. Brasília: Presidência da República, 1996. Disponível em: <http:// www.planalto.gov.br/ccivil_03/Leis/L9394.htm >. Acesso em: 20 maio 2009.

Lei $n^{\circ}$ 10.172, de 9 de janeiro de 2001. Aprova o Plano Nacional de Educação e dá outras providências. Brasília: Presidência da República, 2001. Disponível em <https:// www.planalto.gov.br/ccivil_03/leis/leis_2001/110172.htm>. Acesso em: 20 maio 2009.

Ministério da Educação e do Desporto. Parâmetros curriculares nacionais. Brasília, 1997. Disponível em <http://www.mec.gov.br/ >. Acesso em: 22 abr. 2010.

BYRNE, B. M. Structural equation modeling with Lisrel, Prelis and Simples: basic concepts, applications and programming. New Jersey: Lawrence Erlbaum, 1998.

CÁCERES GÓMEZ, S. Los estudios ciencia, tecnología y sociedad y la educación para el desarrollo. Ingenieria sin Fronteras: revista de cooperación, Madrid, n. 14, 2001.

CARDOSO, T. F. L. Sociedade e desenvolvimento tecnológico: uma abordagem histórica. In: GRINSPUN, M. P. S. Z. (Org.). Educação tecnológica: desafios e pespectivas. São Paulo: Cortez, 2001. p. 183-225. 
Concepções de tecnologia de graduandos ...

CARRANZA, C. C. Nuevas tecnologías y sostenibilidad ambiental y humana. Ingenieria sin Fronteras: revista de cooperación, Madrid, n. 14, 2001. Disponível em: <http:// socios.ingenieriasinfronteras.org/revista/articulos/14/revista14.htm $>$. Acesso em: $6 \mathrm{fev}$ 2009.

COLOMBO, C. R.; BAZZO, W. A. Educação tecnológica contextualizada, ferramenta essencial para o desenvolvimento social brasileiro. [S.1.]: OEI, 2002. Disponível em: <http://www.oei.es/salactsi/colombo.htm>. Acesso: 6 fev. 2009.

CORAZZA, R. I. Inovação tecnológica e demandas ambientais: notas sobre o caso da indústria brasileira de papel e celulose. 1996. 151 f. Dissertação (Mestrado em Política Científica e Tecnológica) - Instituto de Geociências, Universidade Estadual de Campinas, Campinas, 1996.

Políticas públicas para tecnologias mais limpas: uma análise das contribuições da economia do meio ambiente. 2004. 291 f. Tese (Doutorado em Política Científica e Tecnológica) - Instituto de Geociências, Universidade Estadual de Campinas, Campinas, 2004.

Tecnologia e meio ambiente no debate sobre os limites do crescimento: notas à luz de contribuições selecionadas de Georgescu-Roegen. Economia, Brasília, v. 6, n. 2, p. 435-461, 2005. Disponível em: <http://www.anpec.org.br/revista/vol6/ vol6n2p435_461.pdf>. Acesso em: 12 ago. 2013.

DAGNINO, R. Um debate sobre a tecnociência: neutralidade da ciência e determinismo tecnológico. Campinas: Unicamp, 2007. Disponível em: <http://www.ige.unicamp.br/site/ aulas/138/UM_DEBATE_SOBRE_A_TECNOCIENCIA_DAGNINO.pdf > . Acesso em: 8 jan. 2009.

DUCASSÉ, P. História das técnicas. São Paulo: Europa-América, 1987.

DURÁN CARRERA, A. Nuevas tecnologías y viejos debates: algunas ideas sobre la participación social. Ingenieria sin Fronteras: revista de cooperación, Madrid, n. 14, p. 1-7, 2001.

FIRME, R. N.; AMARAL, E. M. R. Concepções de professores de química sobre ciência, tecnologia, sociedade e suas inter-relações: um estudo preliminar para o desenvolvimento de abordagens CTS em sala de aula. Ciência \& Educação, Bauru, v. 14, n. 2, p. 251-269, 2008.

FORAY, D.; GRÜBLER, A. Technology and the environment: an overview. Technological Forecasting and Social Change, New York, v. 53, n. 1, p. 3-13, set. 1996.

FÓRUM DE PRÓ-REITORES DE GRADUAÇÃO DAS UNIVERSIDADES BRASILEIRAS. Diretrizes curriculares para os cursos de graduação. Texto aprovado em 12/09/2000. Disponível em: < http://portal.mec.gov.br/sesu/arquivos/pdf/ DocDiretoria.pdf >. Acesso em: 12 ago. 2013. 
Veraszto, E. V. et al.

Educação a distância (EAD) na graduação: as políticas e as práticas. Curitiba, 2001. Disponível em: <http://www.forgrad.com.br/documentos/publicacoes/ publicacao_2_parte_7.zip>. Acesso em: 20 maio 2009.

FREEMAN, C. The greening of technology and models of innovation. Technological Forecasting and Social Change, New York, v. 53, n. 1, p. 27-39, Sep. 1996.

GAMA, R. A tecnologia e o trabalho na história. São Paulo: Nobel: Edusp, 1987.

GONZÁLEZ GARCÍA, M. I. G.; LÓPEZ CEREZO, J. A.; LUJÁN LÓPEZ, J. L. Ciencia, tecnologia y sociedad: una introducción al estudio social de la ciencia y la tecnología. Madrid: Tecnos, 2000.

HAIR JR., J. F. et al. Análise multivariada de dados. 5. ed. Porto Alegre: Bookman, 2005.

HANCOCK, G. R.; MUELLER, R. O. (Org). Structural equation modeling: a segund course. Greenwich: Information Age, 2006.

HAYDUK, L. A. Structural equation modeling with Lisrel: essentials and advances. Baltimore: The Johns Hopkins University Press, 1987.

HERRERA, A. et al. Las nuevas tecnologías y el futuro de América Latina: riesgo y oportunidad. México: Editorial de la Universidad de las Naciones Unidas: Siglo Veintiuno, 1994.

HILST, V. L. S. A tecnologia necessária: uma nova pedagogia para os cursos de formação de nível superior. Piracicaba: Editora da UNIMEP. 1994.

JACINSKI, E.; SUSIN, R. M.; BAZZO, W. A. Repensando as dicotomias entre tecnologia e sociedade na educação tecnológica. Revista Brasileira de Ensino de Ciência e Tecnologia, Ponta Grossa, v. 1, n. 3, p. 13-22, 2008.

JÖRESKOG, K.; SÖRBOM, D. Structural equation modeling with the SIMPLES command language. Lincolnwood: Scientific Software International, 1993.

2001.

LISREL 8: user's reference guide. Lincolnwood: Scientific Software International,

LISREL 8.54: student edition. Lincolnwood: Scientific Software International, 2003.

LAYTON, D. Revaluing the T in STS. International Journal of Science Education, London, v. 10, n. 4, p. 367-378, 1988.

LÉVY, P. As tecnologias da inteligência: o futuro do pensamento na era da informática. São Paulo: 34, 1993.

LION, C. G. Mitos e realidades na tecnologia educacional. In: LITWIN, E. (Org.). Tecnologia educacional: política, histórias e propostas. Porto Alegre: Artes Médicas, 1997. p. 23-36. 
Concepções de tecnologia de graduandos ...

MAIZTEGUI, A. et al., C. Papel de la tecnología en la educación científica: una dimensión olvidada. Revista Iberoamericana de Educación, Madrid, n. 28, p. 129-155, 2002.

MALHOTRA, N. K. Pesquisa de marketing: uma orientação aplicada. 3. ed. Porto Alegre: Bookman, 2001.

MARTÍN GORDILLO, M. (Coord.). Ciencia, tecnología y sociedad. Proyecto Argo. Materiales para la educación CTS. [S. 1.]: OEI, 2001. Disponível em: <http://www.oei.es/ salactsi/argo02.htm>. Acesso em: 19 jan. 2003.

MARTÍN GORDILLO, M. M.; GONZÁLEZ GALBARTE, J. C. Reflexiones sobre la educación tecnológica desde el enfoque CTS. Revista Iberoamericana de Educación, Madrid, n. 28, p. 17-59, 2002.

MARUYAMA, G. M. Basics of structural equation modeling. Thousand Oaks: Sage, 1998.

MEADOWS, D. H. et al. The limits to growth. New York: Universe Books, 1972.

OSORIO M., C. La educación científica y tecnológica desde el enfoque en ciencia, tecnología y sociedad: aproximaciones y experiencias para la educación secundaria. Revista Iberoamericana de Educación, Madrid, n. 28, p. 61-82, 2002.

PACEY, A. The culture of technology. Cambridge: MIT Press, 1983.

PINHEIRO, N. A. M.; SILVEIRA, R. M. C. F.; BAZZO, W. A. Ciência, tecnologia e sociedade: a relevância do enfoque CTS para o contexto do ensino médio. Ciência $\boldsymbol{\&}$ Educação, Bauru, v. 13, n. 1, p. 71-84, 2007.

REIS, J. B. A. O conceito de tecnologia e tecnologia educacional para alunos do ensino médio e superior. In: CONGRESSO DE LEITURA DO BRASIL, 17., 2009, Campinas.

Anais... Disponível em: < http://www.alb.com.br/anais17/txtcompletos/sem16/ COLE_932.pdf >. Acesso em: 26 abr. 2010.

RICARDO, E. C.; CUSTÓDIO, J. F.; RESENDE JUNIOR, M. F. A tecnologia como referência dos saberes escolares: perspectivas teóricas e concepções dos professores.

Revista Brasileira de ensino de Física, São Paulo, v. 29, n. 1, p. 135-147, 2007.

RODRIGUES, A. M. M. Por uma filosofia da tecnologia. In: GRINSPUN, M. P. S. Z.

(Org.). Educação tecnológica: desafios e pespectivas. São Paulo: Cortez, 2001. p. 75-129.

SANCHO, J. M. (Org.). Para uma tecnologia educacional. Porto Alegre: Artmed, 1998.

SILVA, C. A. D. et al. O movimento ciência, tecnologia e sociedade e o ensino tecnológico: uma revisão bibliográfica. In: CONGRESSO BRASILEIRO DE ENGENHARIA MECÂNICA, 15., 1999, Águas de Lindóia. Anais... . São Paulo: ABCM; Campinas: Unicamp, 1999. 1 CD-ROM.

SILVA, D.; BARROS FILHO, J. Concepções de alunos do curso de pedagogia sobre a tecnologia e suas relações sociais: análise de um pré-teste. Educação e Ensino, Bragança Paulista, v. 2, n. 6, p. 14-31, 2001. 
Veraszto, E. V. et al.

SILVA, D. et al. Atividades de ciência, tecnologia e sociedade (CTS) para as disciplinas dos cursos de administração de empresas. Revista Álvares Penteado, São Paulo, n. 4, p. 47-67, 2000 .

SIMON, F. O. et al. Habilidades e competências de engenheiros sob a ótica dos alunos dos cursos de engenharia. In: CONGRESSO BRASILEIRO DE EDUCAÇÃO EM ENGENHARIA, 32., 2004, Brasília. Anais... Brasilia : Cobenge, 2004a. p. 1-7.

SIMON, F. O. et al. Uma proposta de alfabetização tecnológica no ensino fundamental usando situações práticas e contextualizadas. In: CONGRESO DE HISTORIA DE LAS CIENCIAS Y LA TECNOLOGÍA, 6., 2004, Buenos Aires. Resúmenes... Buenos Aires: Sociedad Latinoamericana de Historia de las Ciencias e la Tecnología, 2004b. 1 CD-ROM.

TOLMASQUIM, A. T. Instrumentalização e simulação como paradigmas da ciência moderna. In: D’AMBROSIO, U. (Org.). Anais do $2^{\mathbf{0}}$ Congresso Latino-Americano de História da Ciência e da Tecnologia. São Paulo: Nova Stella, 1989. p. 83-87.

VALDÉS, P. et al. Implicaciones de la relaciones ciencia-tecnología en la educación científica. Revista Iberoamericana de Educación, Madrid, n. 28, 101-127, 2002.

VARGAS, M. Prefácio. In: GRINSPUN, M. P. S. Z. (Org.). Educação tecnológica: desafios e perspectivas. São Paulo: Cortez. 2001. p. 7-23.

VERASZTO, E. V. Projeto Teckids: educação tecnológica no ensino fundamental. 2004. 184 f. Dissertação (Mestrado em Educação) - Faculdade de Educação, Universidade Estadual de Campinas, Campinas, 2004.

Tecnologia e sociedade: relações de casualidade entre concepções e atitudes de graduandos do Estado de São Paulo. 2009. 284 f. Tese (Doutorado) - Faculdade de Educação, Universidade Estadual de Campinas, Campinas, 2009.

VERASZTO, E. V. et al. Ensino de física e tecnologia: desenvolvimento de atividades de educação tecnológica para alunos do ensino fundamental. In: GARCIA, N. M. D. (Org.). Atas do XV Simpósio Nacional de Ensino de Física. Curitiba: CEFET, 2003 a. p. 1974-1983. 1 CD-ROM.

O caráter multidisciplinar da educação tecnológica: desenvolvendo atividades práticas contextualizadas a partir de uma releitura dos parâmetros curriculares nacionais In: DESAFIOS da educação neste século: pesquisa e formação de professores. Cruz Alta: Centro Gráfico Unicruz, 2003b. v. 2.

Tecnologia: buscando uma definição para o conceito. Prisma.com: revista de ciências e tecnologias de informação e comunicação, Porto, n. 7, p. 60-85, 2008.

. Estudios CTS en Brasil: relación causal entre concepciones y actitudes de estudiantes universitarios del Estado de São Paulo frente al desarrollo tecnológico. Icono 14: revista de comunicación, educación y TIC, Madrid, v. 1, p. 407-424, 2009. 
Concepções de tecnologia de graduandos ...

VIEIRA, R. M.; MARTINS, I. P. Formação de professores principiantes do ensino básico: suas concepções sobre ciência-tecnologia-sociedade. Revista Iberoamericana de Ciencia, Tecnología y Sociedad, Buenos Aires, v. 2, n. 6, p. 101-121, 2005.

WINNER, L. La ballena e el reactor: una búsqueda de los límites en la era de la alta tecnología. 2. ed. Barcelona: Gedisa, 2008.

WORLD COMMISSION ON ENVIRONMENT AND DEVELOPMENT. Our common future. Oxford: Oxford University Press, 1987. 